\title{
Neuroimaging and clinical presentation of stroke developing concurrently with herpes zoster
}

Sir,

A 48-year-old woman admitted to our center with complaints of right-sided facial weakness, lisping, and apathetic mood changes which started abruptly 2 days ago. Her complaints had not progressed and because of her social problems she had not applied to another health center earlier. On her medical history, it was learned that she was on follow-up due to the type 2 diabetes mellitus for 2 years, and she had been suffering from reoccurring oral shingles (approximately bimonthly) which had occurred this time concurrently to her neurological symptoms on her left anguli oris. Physical examination was normal except left oral vesicular lesions compatible with herpes zoster (HZ) [Figure 1]. Neurological 
examination revealed right-sided central facial paralysis, and she was disregarding her complaints that were evaluated as apathetic. Cranial magnetic resonance imaging (MRI) showed diffusion restriction in left corona radiata and basal ganglia in the territory of lenticulostriate arteries. MRI did not yield any other chronic lesion [Figure 2]. With the diagnosis of stroke, intravenous heparin, and oral aspirin therapy were started. Cranial computed tomography angiography, performed the same day, revealed normal left M1 (middle cerebral artery first segment). Further investigations for etiological evaluation were unremarkable (Hemogram, Biochemistry, B12, folate, lipid profile, Coagulation Mutation Panel [Factor ${ }^{2,5,7,8}$, MTHFR, prothrombin G20210A mutation, Factor V Leiden], echocardiography, $24 \mathrm{~h}$ Holter monitoring). Hence, she was discharged with aspirin $300 \mathrm{mg}$ therapy and the suggestions of dermatology outpatient control. In the follow-up, her neurological condition improved

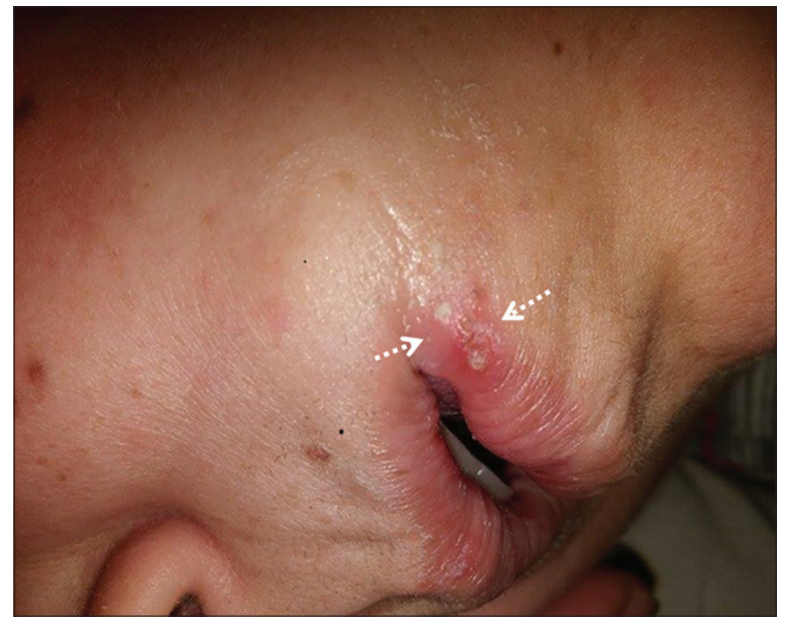

Figure 1: Erythematous vesicular lesions in left oral mucosa (arrows) moderately; MRI 1 year after did not show any lesion other than sequel region in stroke site and neuropsychological assessment revealed normal cognitive functions.

$\mathrm{HZ}$ is an infection occurring due to reactivation of varicella zoster virus (VZV) from its latent state in sensory ganglia, including trigeminal ganglion. ${ }^{[1]}$ Over the past decades, various reports of vascular disease associated with VZV reactivation have been published. On the other hand, although its role in vasculopathy has been elucidated significantly in pediatric population, the clinical manifestations and incidence of VZV vasculopathy in adults has still need to be clarified. ${ }^{[2]}$ Breuer et al. suggested $\mathrm{HZ}$ as an independent risk factor for vascular disease in the result of their retrospective cohort study. ${ }^{[1]}$ Based on the previous reports, they argued a possible cranial artery pathology developing due to VZV infection arising via afferent branches of the trigeminal nerve. ${ }^{[1,2]}$ They also argued inflammatory response associated with VZV infection as another mechanism that can be responsible preferentially from transiently (in the short term period) increased risk of stroke following HZ. ${ }^{[1,3]}$ In this report, I present a rare case at whom concurrent $\mathrm{HZ}$ was found to be the most probable risk factor for stroke. Botulinum toxin A resulted as normal including left M1, however, a possible arterial pathology in lenticulostriate arteries may be overlooked. At this point, I would like to emphasize that not any additional lesion was seen on MRI at the time of incidence as well as in the $1^{\text {st }}$ year follow-up MRI, which may suggest a transient and local vascular flow problem as the responsible pathomechanism of stroke. In my opinion, a local thrombotic process associated with the VZV inflammation may be the most likely etiological factor rather than an extensive pathology of vasculopathy

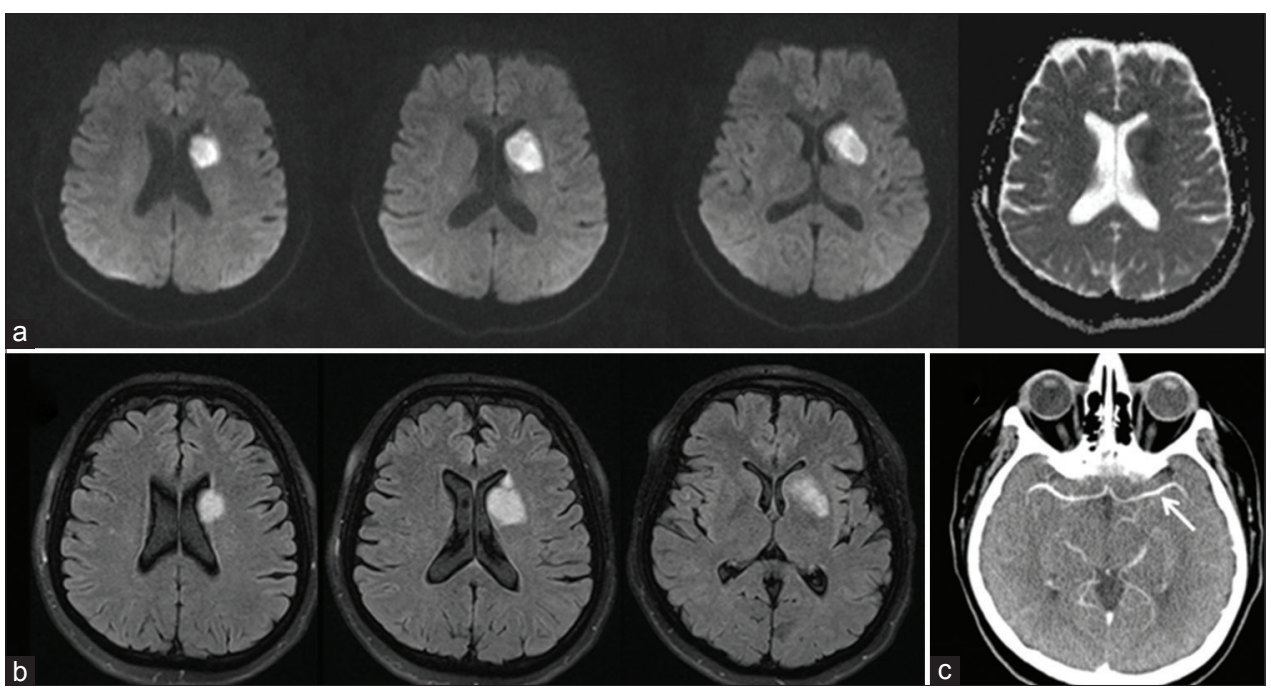

Figure 2: (a) Diffusion-weighted imaging and apparent diffusion coefficient sequences showing restricted diffusion in the corona radiata and basal ganglia corresponding to the territories of the left lenticulostriate arteries. (b) Fluid attenuation inversion recovery sequences showing hyperintensity in the same regions. (c) Brain tomography angiography showing intact left M1 segment 
as hypothesized by Minassian et al. ${ }^{[3]}$ The association between $\mathrm{HZ}$ and stroke has been clearly revealed in recent large case studies, however underlying pathogenesis has not been clarified yet. ${ }^{[2,4]}$ Gathering these knowledges, this report constitutes a considerably rare, detailed clinical-neuroimaging illustration of this co-occurrence. Thus, this case may probably give important points regarding the pathogenesis of stroke in association with acute HZ. However, future prospective studies including results of conventional angiography and pathological investigations need to be conducted to clarify this issue. Finally, through this demonstrative case, I would again point out the importance of $\mathrm{HZ}$ among etiological factors of stroke and remark keeping in mind HZ during the routine evaluation process of stroke patients.

\section{Financial support and sponsorship}

Nil.

\section{Conflicts of interest}

There are no conflicts of interest.

Halil Onder
Department of Neurology, Hacettepe University Hospital,
Ankara, Turkey
Address for correspondence:
Dr. Halil Onder,
Department of Neurology, Hacettepe University
Hospital, Sihhiye 6410, Ankara, Turkey.
E-mail: halilnder@yahoo.com

\section{References}

1. Breuer J. Varicella zoster. In: Zuckerman AJ, Banatvala JE, Schoub BD, Griffiths PD, Mortimer P, editors. Principles and Practice of Clinical Virology. ${ }^{\text {th }}$ ed. Chichester: Judith Breue; 2009.

2. Gilden D, Cohrs RJ, Mahalingam R, Nagel MA. Varicella zoster virus vasculopathies: Diverse clinical manifestations, laboratory features, pathogenesis, and treatment. Lancet Neurol 2009;8:731-40.

3. Minassian C, Thomas SL, Smeeth L, Douglas I, Brauer R, Langan SM. Acute cardiovascular events after herpes zoster: A self-controlled case series analysis in vaccinated and unvaccinated older residents of the United States. PLoS Med 2015;12:E1001919.

4. Breuer J, Pacou M, Gauthier A, Brown MM. Herpes zoster as a risk factor for stroke and TIA: A retrospective cohort study in the UK. Neurology 2014;82:206-12.

This is an open access article distributed under the terms of the Creative Commons Attribution-NonCommercial-ShareAlike 3.0 License, which allows others to remix, tweak, and build upon the work non-commercially, as long as the author is credited and the new creations are licensed under the identical terms.

\begin{tabular}{|l|l|}
\hline \multicolumn{2}{|c|}{ Access this article online } \\
\hline Quick Response Code: & Website: \\
\hline & www.ruralneuropractice.com \\
\cline { 2 - 3 } & \\
\hline$\square$ & DOI: \\
\hline
\end{tabular}

How to cite this article: Onder $\mathrm{H}$. Neuroimaging and clinica presentation of stroke developing concurrently with herpes zoster. J Neurosci Rural Pract 2016;7:465-7. 